\title{
Developing pedagogies for a synchronous online course on teaching pre-university mathematics
}

\author{
Jennie Golding and Nicola Bretscher, UCL Institute of Education
}

\begin{abstract}
Online education is widely heralded as cost-effective and convenient, but there is a recognised need to research appropriate pedagogies for synchronous online (SOL) teaching. Prior research suggests that course design, including formative assessment, is critical in achieving accessible and flexible learning episodes. We harness a well-tested theoretical framework to analyse the development of pedagogies for synchronous online mathematics teacher education in a course designed to induct early career teachers into pre-university teaching. The lenses of 'teaching-', 'social-', 'learner-', and 'cognitivepresence' reveal opportunities for improving provision. We show participants' learning of mathematics content knowledge can then appear comparable to that achieved face-to-face, but it is more challenging to design for the growth of mathematics pedagogical knowledge in a synchronous online environment. Many digital tools work well in this medium, but the use of physical tools requires significant development before teacher engagement compares with that achieved face-to-face. However, some approaches developed to address challenges within a synchronous online course appear to have benefits also for face-to-face learning.
\end{abstract}

Keywords: online pedagogy, synchronous online, pre-university mathematics, formative assessment, social presence, cognitive presence

\section{Introduction}

Policymakers perceive clear advantages for developing online courses to address limitations and geographic unevenness of systemic expertise (Alexander et al, 2007). Such courses are viewed as efficient in terms of participant and presenter time and money (Kissau, 2014), though Comas-Quinn (2011) points to what can be significant technology-related challenges for both presenters and participants. Within the particular field of synchronous online (SOL) teacher professional development, such advantages are well-evidenced (e.g. de Pomerai and Tripconey, 2011). In addition, it is widely assumed (Bates et al, 
2016) that SOL presentation offers most of the learning benefits available face-to-face. However, there is little evidence to support such assumptions. This paper offers particulars of some possible affordances and constraints of online teacher professional development, through analysing our developing pedagogies for a SOL course on teaching pre-university mathematics.

Advanced Mathematics Teaching in Early Career (AMTEC) is a short course for beginner and early career teachers of mathematics wanting to teach 'A-Level', the standard calculus-rich pre-university qualification in England. It is offered outside standard initial and early-career development structures, so participants actively opt into it. The course has been developed iteratively over several years and operates in two modes - a three-day face-to-face workshop or ten twilight SOL sessions at weekly intervals - as described in Smith and Bretscher (this volume). In each mode, the materials used are very similar, and delivered by the same team (five teacher educators in all, including the authors). A guiding approach was that of modelling teacher behaviours (as described in Smith and Bretscher, this volume), following Joubert and Sutherland's (2009, p21) recommendation that '...the design of professional development should follow that of good [classroom] practice'. A second approach recognised the centrality of formative assessment for effective learning (e.g. Hodgen and Wiliam, 2006), so we were sensitive to opportunities within the SOL software for both using formative assessment to guide our teaching and being seen to model that use. From the beginning of online course development, we were aware that our preferred classroom pedagogies would not transfer directly to a webinar. It was therefore important to ask, as suggested by Comas-Quinn (2011), 'What pedagogies support learning in the synchronous online AMTEC course?'

Here we offer an account of our related learning, and the frameworks harnessed to analyse what 'improving provision' might mean in this context. The similarities between our two modes offer an unusual opportunity to illuminate their affordances and constraints in the case of teacher education, in particular for teaching pre-university mathematics. Some of our 'findings' are known in the literature, but we report their challenges to us as newcomers to SOL, and in this particular context; others challenge established wisdom in the field.

We first outline our orientation to teacher learning and then examine the AMTEC SOL context to justify the theoretical frameworks adopted for analysis of our pedagogical approaches. For purposes of clarity 
throughout the paper, we use 'presenter' or 'supporting presenter' here to denote teacher educators, and refer to early career teachers attending the AMTEC course as 'participants'.

\section{Orientation to teacher learning}

Given our own backgrounds as mathematics teachers with largely constructivist beliefs about the nature of learning, we came to AMTEC with well-developed beliefs about productive approaches for teaching different areas of the A-level curriculum face-to-face, including through the harnessing of digital technologies in school/college classrooms. We espouse the active, cognitively challenging but supportive approaches identified in Anthony and Walshaw (2009), operationalised in ways our experiences suggest are appropriate for post-16 learners of pre-university mathematics. In AMTEC we endeavour to apply those within a context of effective adult learning (e.g. Merriam, 2001). For example, participant reflection on learning is supported by the use of 'Reflective logs' they are asked to complete after each session, summarising their 'takeaway' learning and any outstanding issues to follow up, for each of subject knowledge and subject pedagogical knowledge.

In designing the course we were influenced by our understanding of what it is that participants need to bring to the classroom - their knowledge, skills and affect (Golding, 2017) - and drew in particular on Ball et al's (2008) analysis of subject content knowledge (SCK) and subject pedagogical knowledge (SPK), with Baumert et al (2012) showing these are distinct and that SPK depends on sufficient SCK. Additionally, we set out to support development of participant self-efficacy, especially for teaching mechanics and statistics, newly-mandated A-level strands which may be new to many of our participants. In both modes, we are therefore careful to probe the range of participant confidence and experience overtly, and to support a participant belief that with suitable preparation, they can acquire the necessary knowledge and skills.

The course aims to induct beginner and early career teachers into teaching A-Level by revisiting key ideas in A-Level Mathematics in 'teacherly' ways. In parallel, we aim to develop subject pedagogy in ways that reinforce and extend messages we might want participants to have about teaching younger students. Our experience is that for many beginner teachers, fluency with A-level mathematics content is at best rusty, and not infrequently conceptually superficial: we cite specifics below. The dual focus is there- 
fore central to both design and to our analysis of what it might mean to 'improve our approaches'. To the first end, we employ tasks designed and presented with participants' 'purpose' and 'utility' (Ainley, Pratt and Hansen, 2006) in mind: the purpose is to enhance both participants' subject knowledge, and (its utility to them as teachers) recognition of how, when and why they could support development of related mathematical functioning in their students. We therefore frequently model how tasks may be used to support mathematical reasoning, and engage participants in critical reflection of the modelled approaches to pedagogy. Because we want participants to be able easily to transfer their experiences to their own face-to-face classrooms, and consider that key to genuine utility to them, we make use of digital technologies we would use in our own mathematics classrooms, but do not fully mine the technological potential of an online course where that would threaten transferability to participants' own classrooms. We explore this issue in discussion.

\section{SOL teaching and learning in AMTEC: a theoretical approach}

We drew data from two Spring 2017 presentations of the course (and Autumn 2017 follow-up): one SOL and one face-to-face, each presentation exclusively in one mode. The report is therefore of teacher educators' learning from prior presentations as well as our analysis of the state of presenters' pedagogies, and participants' learning, in Spring 2017.

In the case of SOL sessions using Blackboard Collaborate software, the supporting presenter monitors and responds to participants' comments and queries in the 'chatbox', sometimes initiating contributions of their own. The materials in the two modes, including organising slides, and tasks employed, are similar: some small differences adopted are explained below. In particular, target subject knowledge and subject pedagogical knowledge content, key pedagogic messages, and the participant reflective logs provided, are identical. So far as we can tell from the background solicited on enrolment, the two groups studied were similarly placed to learn from the course.

We do not give participants access to microphones or to break-out rooms in the webinar version because of time and technological limitations, and throughout it should be borne in mind that our findings are specific to both the AMTEC valued learning outcomes, and the specific operationalisation of the webinar technology. 
Much of the research in the wider field of 'online learning' features asynchronous learning. There is some critique of 'online' (asynchronous) learning in the field of initial teacher education: Alexander et al $(2007$, p214) conclude that 'some teacher preparation courses are not suited for an online format', and Kissau's (2014) study similarly indicated that online instruction is a viable approach when transmitting course content, but less effective than face-to-face instruction when it comes to applying that content in the classroom, largely, he suggests, because potential teachers are unable to witness the demonstration of 'instructional strategies'. We expected SOL learning to be less problematic: it is often regarded as 'blended', with facets of each of face-to-face and asynchronous online learning.

A number of studies of online or blended learning analyse data using Garrison et al's (2010) 'Community of Inquiry' (Col) model, and we were keen to investigate its application to our situation, both so as to make links with other digital education literature and because we felt such an analysis might reveal areas of our pedagogic practice ripe for development. The model was developed in situations where an asynchronous 'learning community' has been established and, based on collaborative constructivist principles, has three interacting elements - social, cognitive and teaching presences - which interact to determine what is available to the learning situation. Each contains dimensions, ordered to highlight their progressive nature, as follows:

- social presence - ability of participants to identify with the course, communicate purposefully in a trusting environment, and develop inter-personal relationships with presenters and other participants.

- cognitive presence - operationalised as four time-ordered phases of participant activity: taskconception ('trigger event'), exploration, making sense of ideas ('integration'), and testing and applying plausible solutions ('resolution'). It is on this cognitive presence that learning directly depends

- teaching presence - presenter task-design, facilitation and direction of discourse to support learning. These dimensions shape the mathematical and pedagogical ideas and the social possibilities made available.

Shea and Bidjerano (2010) develop this model and propose a fourth construct which they call 'learner presence', characterised as a combination of participant self-efficacy in relation to course aims, individual application, and effort. A range of evidence, summarized by Annand (2011), suggests, importantly, 
that teaching, social and learner presence serve largely, but not independently, to influence the critical cognitive presence, as in Figure 1.

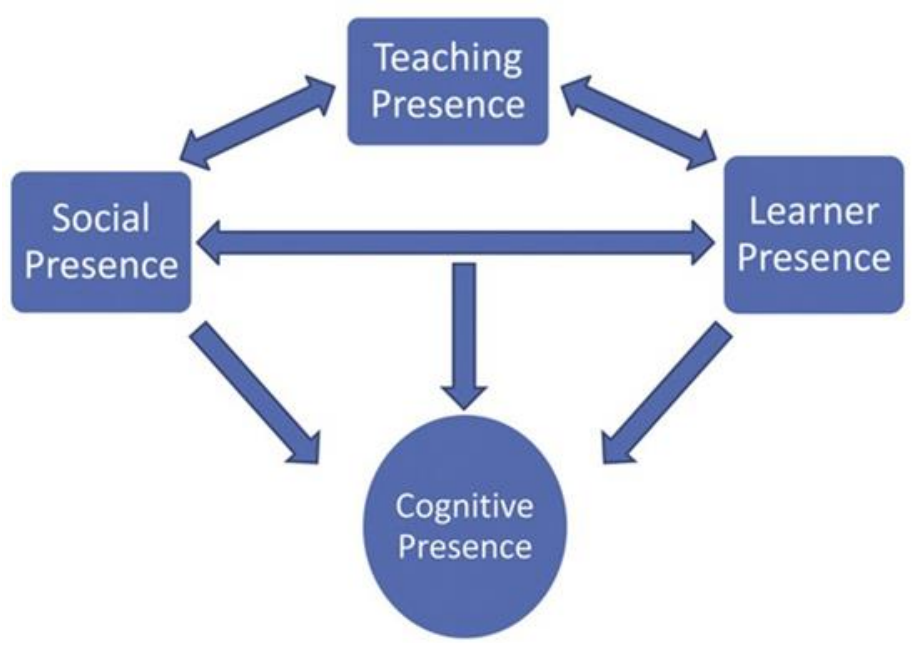

Figure 1: Relationships between Shea and Bidjerano's 'presences' (Annand, 2011)

However, there are some theoretical difficulties in applying the Col model to our situation, which we would characterise as setting out rather to establish a 'professional learning community' (Hord, 1997). In particular, the espoused model of cognitive presence does not transfer well to our course as regards participants' autonomy over goals and tasks. In terms of subject knowledge development, the tasks we employ emphasise engagement in and through mathematical reasoning, rather than enquiry. We aim to develop mathematics pedagogy in part by participants role-playing as Year 12 students, before pivoting to focus on and analyse the pedagogy modelled. We then move closer to a Col by opening up our pedagogic choices to reflection and critique, drawing on participants' own experiences as classroom teachers and thereby ceding some of our 'expert' authority. Nevertheless, we cannot achieve a 'true' Col since inevitably some power imbalance remains and there is limited, or no, scope for participants to explore the modelled pedagogy in the context of their own classroom within the duration of the course. In SOL, employing an enquiry model seems particularly problematic in terms of developing pedagogy since our ability to authentically model classroom approaches in an online setting is limited. Exploring and reflecting upon the pedagogic choices taken is likely to be constrained, though the structure of the SOL course is such that some participants can explore possibilities between sessions. However, while maintaining 
criticality and an openness to further development of these ideas, we found the four 'presences' helpful as core 'a priori' themes for analysis - and indeed, for our in-course reflection on and evaluation of our teaching.

\section{The study}

Research design centred on collecting data that might afford insight into Shea and Bidjerano's (2010) four 'presences'. Data comprised 1.25-hour video recordings of sessions four and seven in both modes, and transcriptions of audio-recorded thirty minute semi-structured interviews with a small focus-group of 'core' participants and, separately, with presenters and supporting presenters, including the authors, in each mode, after each of sessions four, seven and ten. We collected completed reflective logs (Jones and Ryan 2014) from all focus-group participants and any other volunteering participants ( $n=21$ for SOL, $\mathrm{n}=39$ from two parallel face-to-face groups). These were complemented by semi-structured interviews with core participants in September 2017 to reflect upon medium term learning, as well as parallel informal feedback from all participants solicited by email and focused on classroom impact. Additionally, an external colleague spent a day observing the face-to-face course and offered feedback that has informed our analysis.

We acknowledge the threats to validity of such approaches, especially as we have no direct evidence of the classroom application of participants' claimed enhanced SCK or SPK, but the variety of sources of data served to triangulate aspects of presenters' accounts. Attention to the first author's accounts as presenter of the study focus sessions, and her reports of video-related intended learning, required particular reflexivity and challenge. Threats to validity of participant interviews were addressed by paying attention to e.g. building up empathy, active listening, and active clarification of responses. Nevertheless, it remains the case that our direct access to participants' learning, and sometimes to presenters' learning, - and so to confidence that pedagogical approaches are developing - is limited.

The study examined the development of presenter pedagogy and reported participant learning over the course as a whole, but focused particularly two sessions Differentiation and Newton's Laws, led by the same presenter (the first author) in both modes. The motivation for this focus was that they each model the use of particular tools to support student learning: the deliberate use of such tools is one of the key pedagogic foci of the AMTEC course. In Differentiation we model the use of Geogebra (dynamic geometry software) as a tool to link functions with their gradient functions visually, predicting and explaining 
graphical behaviours and supporting link-making between different conceptualisations of differentiation. In the face-to-face version of Newton's Laws we carry out physical experiments with tools such as bathroom scales; however in the online version of this session, modelling such tool use is more problematic. Additionally, previous experience with these sessions suggested the related mathematics content (fundamental concepts related to differentiation, and a relatively rigorous introduction to Newtonian mechanics) is challenging for many participants. These two sessions were therefore selected as very different and potentially 'telling' (Mitchell, 1984) cases.

Interviews were designed to probe potential areas of difference between the two modes, informed by the literature and our own reflection, whilst remaining open to probing emergent issues, as described below. In this sense, any of the forms of data collected could potentially provide insight into any of the four presences. Presenter interviews and session recordings particularly evidenced teaching presence, whilst interviews with core participants focused on participant-facing presences, with reflective logs giving particular insight into cognitive presence. Interview design and approach to analysis are discussed below.

Some aspects were self-evidently different. The face-to-face course was delivered intensively over three consecutive days, with three or four different content foci each day. The SOL course was twilight during term-time, so participants were attending sessions spaced over ten weeks and after a day's teaching. The literature (e.g. Joubert and Sutherland, 2009) suggests such sustained exposure to key ideas can contribute to effective teacher learning (teaching presence). In addition, the SOL course made AMTEC accessible to potential participants beyond those who could commit to a 3-day course in a particular location during school holidays. Online participants (and new presenters) had to familiarise themselves with SOL software and available means of communication, and we took some care to support this. The potential for available tools was different - for example, SOL participants can 'vote' or make a contribution effectively anonymously (social presence). Participants can review recordings of online sessions (teaching presence), and de Pomeroi and Tripconey (2011) found that highly valued, though none of our participants reported doing so unless they had missed a session. However, in the study reported here, there are no cost advantages for providers, since we enrol groups of 25-35 teachers, delivering with one main presenter and one supporting presenter, in both modes.

There are other aspects of the two modes which our reflection suggested might be different, and these were among the areas probed in interviews. They included participant confidence, self-efficacy and mo- 
tivation during and after the course, up-take of key pedagogic messages, transferability of learning to classroom situations, mental, emotional and physical persistence with the course, effect of group size for manageability and impact, and flexibility of course presentation. Interview design, for both presenters and participants, centred on probing these areas in a semi-structured way, while also offering openings for any other reflections on the pedagogical support for, or constraints on, opportunities for learning in each mode.

Analysis was, at a high level, by 'presence', with grounded sub-themes (Charmaz, 2006) arising from the data: these are described in the findings reported below. Researchers coded independently and crossreferenced, achieving a high degree of agreement. Videos of sessions were analysed by the presenter for purpose of pedagogic decision-making, in relation to both 'presences' and pedagogic intentions for development of each of SCK and PCK. This latter enabled identification of, and reflection on, differences in approaches adopted. Interpretations have been offered to co-presenters, to focus group teachers, and to the external colleague cited, for validation.

\section{Findings and discussion}

SOL-related themes emerging from the data included presenter challenges associated with supporting appropriate social interactions, and approaches they have developed to address those; learners maintaining engagement; presenters using and modelling formative assessment, and using tools in appropriate ways; the relative profiles of subject knowledge and of subject pedagogy evidenced; and reports of transfer to practice. We analyse each of these through the four 'presences' outlined above. We note that both presenters and participants were familiar with the dynamics of face-to-face classrooms and, unsurprisingly, their comments on SOL therefore focused on comparing the affordances and constraints of online pedagogy with these. Although interviews took place within a particular presentation, presenters naturally drew on the range of their experiences across different modes and their accumulated learning from those.

\section{Social presence: developing classroom norms in SOL}


A number of specific approaches have been adopted to develop social presence in SOL sessions e.g. participants placing themselves on a geographic map in introductory sessions, regular requests to show emoticons as a confidence-check, informal conversation before sessions begin, recognition of participants' knowledge and experience, encouraging them to share their thoughts on 'what would work in your school', deliberate support presenter use of the chatbox to make comments and ask questions, with frequent encouragement for students can do this. Such considerations often contribute only tangentially to the subject-specific teacher learning sought, yet underpin willingness to participate in learning-supportive ways. Despite our efforts, not all participants acknowledge even a direct request for response, anonymous or otherwise, let alone ask spontaneous questions, so attempts to establish participative classroom norms have met with only partial success. Data suggest that participants' SOL communicative confidence is a barrier, though this may diminish over the duration of the course:

I feel like I engage with the class differently ...than I would in person. The fact that you write down your questions... if it would have been silly questions, for example, that's much more evident and you can't get rid of it. ...So especially at first I was worried that I was asking something ridiculous [Participant SOL interview 1]

Several presenters claimed in interviews they work hard in an SOL environment to establish a supportive, challenging ethos and to 'know' the group e.g. linking individuals with learning behaviours. Despite this, they still feel they have less grasp of these issues than in a face-to-face situation - due in part to difficulties in maintaining meaningful presenter-supporter-participant communication:

Even if I ask, I can't be sure l'll get 100\% response (online), so proportions of grasping or not, or where along the continuum teachers are, are harder to know, especially as online it'll often be the supporter who's fielding the questions [Presenter]

It is also the case that time and effort has to be devoted to learning to use the software, and there are occasional technical challenges:

You asked us to put dots on the screen but I couldn't find...I couldn't work out how to... (Participant, SOL interview 1) 
Both participants and presenters perceive peer support, enabling collaborative learning, to be an important affordance of face-to-face sessions that is largely lacking in SOL environment.

I noticed [in face-to-face sessions], when we were doing the conceptually harder parts, the informal peer support going on - again, not so easy to provide for online, though as we've seen, encouraging teachers to do the course in pairs or small groups is a potential way forward for that [Presenter]

However, an external colleague observing a face-to-face session commented that he observed some participants dominating, even silencing, those less confident, so the impact of peers face-to-face, as online, can be mixed.

In terms of Garrison et al's (2010) 'social presence' criteria almost all SOL participants appear to identify with the course, some communicate purposefully via the chatbox, but few develop inter-personal relationships with presenters and other participants. Other classroom norms, such as a clear expectation that participants will complete their (private) reflective log at least after each session, are common to both modes.

\section{Learner presence: maintaining concentration and engagement}

In face-to-face sessions, participants engage directly with peers, with slides, with the presenters as they circulate, and with emerging verbal or written thinking. They also have the opportunity to access peer and presenter expertise in breaks between sessions. In contrast, SOL participants are largely engaging with slides, their individual thinking, and sometimes with peers or the support presenter via the chatbox. For some SOL participants, as in Comas-Quinn (2011), this can present significant challenges to maintenance of concentration and engagement, and they might develop less commitment to the learning of the group:

I think the [face-to-face] environment of being surrounded by people who are all learning motivates that part out of me. And you'd be letting the class down if you weren't participating..... Whereas I wasn't held accountable behind the screen. So I suppose I was my worst student.... If you wanted 
you could have it all hands free ...you don't have to be a hundred percent engaged. [SOL participant, interview 3]

Obviously it's got perks of being really convenient that from home you can just turn on your computer and get on with the tasks...but I find myself...and this isn't your fault at all, ...I'll flick in and out ...it's so much easier to do online. [SOL participant, interview 2]

Maintaining concentration can be difficult for supporting presenters too and here again, there is a sense that professional accountability may feel diminished towards 'faceless' course participants:

The other thing that constrains what I can do ...is my zoning out...I'm not so engaged (as in f2f) ...then (on hearing interviewees' voices) it was like, oh, they're real people. [Supporting presenter, SOL]

During the SOL course, live presenter thumbnails were introduced, and tangible benefits were apparent in terms of enhanced learner presence: 'it makes it feel much more like a real classroom, and my attention is less likely to wander' (participant, SOL interview 3) and supporting presenters also reported feeling more engaged.

Other issues related as much to compactness of course as to mode: participants claimed both advantage to having to re-think themselves into the course each week online, and disadvantage to having lost contact with, for example, key pedagogic messages over that week. They suggested a 'gap task' would address this, though their term-time lives are already very busy.

I suppose I wonder ...if you could leave challenges for us...I don't know, whether it could be something pedagogical or like a plenary or ... something. And then you could use that in your classroom and just see how it went. And then you could bring that back. [SOL participant, interview 3]

Face-to-face course participants said they were 'fully available' (physically, mentally and emotionally) for the face-to-face course, but other teacher development literature (Joubert and Sutherland, 2009) suggests they might retain less of the learning benefit from a 'one-shot' concentrated course than from a more extended version. 
Right now we're in the holidays .... I recognise that I would like to improve my maths, so I can focus on this and I don't have to worry about other things. ..But also I suppose it's the setup. Because I know that these three days I'm doing maths, so I'm much more focused. [F2f participant interview 1]

\section{Teaching presence: using and modelling formative assessment}

In interviews our presenters talked about their enjoyment of learning to teach in new ways, including coming to know the particular technological environment adopted: they showed little of the reluctance and overwhelmed response reported by Comas-Quinn (2011), with its negative impact on learners. However, they raised formative assessment as a particular issue in managing online teaching, intimately related to social presence and maintenance of a meaningful presenter-supporter-participant subjectbased dialogue. As noted above, participants felt they were more willing to ask spontaneous questions or suggest risky answers face-to-face, thus offering opportunities for assessment: that was counter to our expectation, as in Kissau (2014), that participants would feel more secure to do so online as they were effectively anonymous. Presenters were able to point to specific occasions face-to-face where they noticed puzzled looks or caught a few tentative questions, often on-table, and deduced that further mathematical support was required:

[in the face-to-face session on Differentiation] I think I noticed it via some small queries around function notation, that I then probed a little, saw some puzzled looks so went a bit further, and then the size of the insecurity started to become apparent. Online, I'd only have noticed that had I asked a particular probing question and then waited for answers to be typed in -or asked for an emoticon - and even then we'd often not get a full response - teachers can hide, in a way it's difficult to in a classroom. [Presenter]

Although presenters encouraged participants to use the 'confused' emoticon if appropriate, they have rarely done so, nor raised questions indicating their uncertainties in SCK, even when, for example, some proved to have poor confidence with the theory of functions and ignorance of differentiation from first principles. Presenters were sensitised to possible student uncertainties by experience in face-to-face sessions, and we note their dependence on that prior experience to proactively probe online. For exam- 
ple, at one stage in Newton's Laws we throw a ball vertically upwards and ask teachers about the salient forces acting on it at different stages of its flight. A key misconception, even among those who studied mechanics at school, is that the projective force persists in addition to the weight. That idea is widely voiced in a face-to-face classroom (as it is with teenagers studying mechanics), yet in our experience, it has been absent from SOL discussion until prompted by a presenter.

We conclude that there are ways of encouraging formative assessment online, for example through emoticons or confidence tables or use of the thumbs-up/down symbol - but these didn't always work well. Face to face, presenters claim that scanning the room begins to build a sense of distribution of confidence/uncertainties. They acknowledge the accuracy of this tacit assessment may be over-estimated, but video analysis suggests not. The SOL environment meant that some different, or insecure, conceptions could have gone unnoticed, so that presenters found it helpful to use prior face-to-face knowledge to surface those.

For learning to teach at this level, some participants claimed in interviews that the overt formative assessment adopted in webinars is more powerful for modelling this aspect of pedagogy than the more subtle 'scanning' and other behaviours presenters adopt face-to-face, though sometimes less (easily) transferable to a classroom environment.

The support presenter proves critical for managing other slowly emergent issues, questions and challenges, and much of the responsibility for formative assessment is necessarily devolved to him/her. For example, in mechanics participants bring a wide range of background knowledge and confidence, and support presenters are sometimes able to direct the more experienced to subtleties of pedagogic implications or of refined models while also supporting beginners in focusing on, for example, the direction and sense of analysis. Whilst chatbox messages are neutral and, for some, relatively unthreatening, it takes time for participants to post and for supporting presenters to respond, and often the main thrust of discussion has moved on by the time an issue has emerged. Appropriate mathematical notation can also be an issue, depending on the software.

You could see all sorts of problems with my entering function notation, and my ability to type and think fast enough was certainly constrained [.....] So when a tricky question comes up I ...go...how am I going to respond to that? What will the chat room allow me to write? And by the time I've done all that.... [SOL support presenter] 
Coordinating input from the presenter and supporter roles is therefore another aspect of using formative assessment online, and both entail challenges:

I did reflect a lot on the role of the support (SOL), which I think ....is even more important than the person presenting...But I felt that at regular intervals I had to make a point in writing so to summarise the discussion. Because there was this conversation in the chat room, not coming from all the participants but from a few of them. And then the lead person would engage with those comments, would make some statements - you know, for ideas, guidance. And then moving on. .... [Presenter]

Further, face-to-face, it is relatively easy for presenters to diverge from intentions in response to perceived interests or needs, for example in the Differentiation session addressing the concept of function, which informal probing a showed to be widely undeveloped. Online, such needs can easily be hidden and in separate, 75-minute sessions deadlines are more strict. Most sessions in the focus face-to-face course exceeded allotted time because presenters had responded in some depth to perceived participant needs, and it was also possible to offer support at other times. In webinars, some deviation is possible and some individual or wider support is given, but largely presenters do not deviate significantly from well-tried core structures, though within those, they expose different presentations and ideas dependent in part on participant response. It is possible such flexibility is not always operationalized wisely, whereas the SOL sessions have the strength of typically enacting the range of carefully planned intended learning opportunities. However, scrutiny of recordings of face-to-face sessions suggests the enacted divergences from the planned course were well-founded in terms of emergent participant learning needs, whether of subject or subject pedagogy.

\section{Teaching presence: physical and digital tool use}

Mode-related differences in the ways tools can be used to support subject knowledge and model pedagogy are most pronounced in relation to physical tools, such as mechanics equipment and whiteboard use. 
In Newton's Laws the session focuses on presenting Newtonian mechanics as an archetypal axiomatic system and follow that through to develop key elementary mechanics principles, their justification, representation and the rigorous presentation of analysis. This is comparatively easy to do in a face-to-face classroom, where presenters (and participants) can throw a ball into the air, stand on bathroom scales and develop ways to change its reading, and then model the associated theorisation. In SOL sessions, the sample session discussed such approaches, but on analysis both participants and presenters felt more could be done to embed participants in their own physical experiments wherever they were working, conjecturing that would support both SCK and SPK development. Both presenters and participants conjectured that the lack of shared physical experience online means that such practical experiments are likely to be less effective than face-to-face:

Surprise hooks people in [re mechanics experiment with bathroom scales], so they really enjoy that [in face-to-face sessions]. I do think I could go further in live online with making links to little practical activities you can do in the classroom, online, perhaps set people up to come with a piece of string and a book and a plastic sandwich box, and apply Newton to those during the session. And we could go back to suggesting they bring a set of bathroom scales to the session, so they 'play' there and then. It's still not a shared experience, as it is in the f2f, of course. [F2f presenter interview 2]

That has since been developed in Autumn 2017, by providing instructions for participants to try experiments 'live' at home, with some success: 'Wow! That's amazing' [Autumn 2017 SOL participant chatbox comment].

A key message in beginning mechanics is to demonstrate the importance of clear, complete diagrams. Online these rapidly become confusing to develop, since screen-writing tools are rather coarse compared with writing on a classroom whiteboard by hand. Pre-prepared online diagrams are clearer, but miss the benefit of being developed responsively and in dialogue with participants, also an important aspect of modelling pedagogy. Similar online constraints in modelling mathematics 'by hand' also appear in the session developing differentiation from first principles, with the associated range of distinctive and precise notation. In face-to-face sessions, presenters choose to model shared discussion and development of each step, as supporting conceptual embedding. Online, such a demonstration is limited to 'revealing' each step and using pointers or highlighting tools to draw attention to the salient mathematics. 
[face-to-face] I omitted slides that could be developed 'live' on the board, because I think that's much more powerful, and allows for participant input to a greater extent....that's particularly important where the conceptual challenge is greater, as in e.g. the development from first principles. We could do more of that online, but the writing tools, particularly when they involve mathematical notation, are fairly crude. I've got better, though, at using online 'emphasis' and 'scanning guide' tools that pick out what I might emphasis with hand-waving, or develop on-board, when it's face-toface [F2f presenter, interview 2].

We invested in tablet technology in the hope of greater facility to model webinar diagram development, but with limited impact on clarity.

By contrast, there appears relatively little difference between modes in the use of our digital tools, such as GeoGebra apps in the Differentiation sessions. The webinar software used has an application-sharing facility so presenters are able to manage software in similar ways across modes. Online, presenters can ask participants to sketch what they think will happen, or write it down, though it still doesn't have the immediacy, or related articulation, of shared mini-whiteboards used in face-to-face sessions, or the easy scanning of a class of whiteboards for learning points ripe for discussion. Nevertheless, both participants and presenters in the Differentiation SOL session felt the quality of content learning was good, and strongly supported by the use of GeoGebra for demonstration and investigation of related key concepts and function behaviours, including graphical links with differentiation from first principles. This last appeared to be novel (or very rusty) subject knowledge for many of our face-to-face participants, and again that is often poorly exposed online, though as above we were able to transfer experience to proactively probe webinar participants' conceptual understanding. Subsequent comments offered suggested considerable growth in related SCK, across both modes, and reflective logs and video recordings supported that.

In terms of Garrison et al's (2010) 'teaching presence', then, both presenter task-design, and facilitation and direction of discourse to support learning, have been iteratively developed for SOL presentation, though challenges remain with both. 
Here, it is appropriate to consider other approaches we could have taken to developing SOL sessions that might capitalise rather more overtly on the potential of the technology: student avatars, perhaps, or use of Newtonian microworlds (e.g. Stevenson, 2002). Our overriding criterion throughout was that participants should see the utility of our adopted approach as one closely related to what they might themselves adopt in the A-level classroom, so supporting development of SPK. Our decisions were based on our understanding of the most effective approaches for a face-to-face classroom. It is possible that by adopting this approach we in fact compromised the learning, especially of SCK, available in webinars.

\section{Cognitive presence: developing subject knowledge and pedagogy}

The presenters' reflections on Newton's Laws exemplify a central difference in affordances between the two modes in terms of modelling pedagogy: the face-to-face environment can mirror to a relatively high degree the possibilities of participants' own classrooms, and that appears reflected in the learning evidenced.

Participant reflective logs show a similar range of depths of reflection across mode. Log entries from SOL participants are usually longer, since face-to-face entries are often time-restricted due to extended sessions. However, SOL participants less frequently mirror key pedagogic messages (Smith and Bretscher, this volume) in their comments, or talk about their pedagogy-related learning, despite analysis of recordings showing comparable degrees of pedagogical attention-drawing/discussion in the two modes. Similar messages emerge from webinar post-session participant interviews. Presenters, too, claim SOL is significantly less effective for modelling pedagogical approaches than face-to-face sessions, though they consider the limitations are less evident in terms of SCK development.

Taken together, this evidence suggests that SOL sessions as currently presented are experienced as less effective supporting development of pedagogical knowledge than subject content knowledge - or that in SOL sessions, some participants do not reach the levels of subject content knowledge necessary for them to focus additionally on development of pedagogic knowledge (e.g. Baumert et al, 2012). Given our knowledge of participants' backgrounds, the former interpretation seems more likely. 


\section{Cognitive presence: evidence of transfer to practice}

Despite the previous caveats, there are indications that the course is having an impact on participant actions at classroom level. SOL participants in pre-session conversation routinely and spontaneously report some impact of the course on both their knowledge and classroom actions for teaching younger students. Similar comments have been made by face-to-face participants in serendipitous meetings. However, follow-up interviews with two face-to-face participants at the start of the new academic year suggest that the main impact for them is improved confidence/knowledge for teaching A-level mathematics. Open feedback on transfer to practice was solicited from participants in Autumn 2017, and most comments, from both modes, centre around enhanced 'big picture' and 'horizon' knowledge, and discipline-specific confidence, enriching teaching of students throughout the secondary phase. Such gains are important for teacher development (Golding, 2017). Specific impact on classroom actions, such as increased use of mini-whiteboards to support mathematical reasoning, was only mentioned by face-toface participants, but that is not necessarily representative of qualitatively differential impact.

Garrison et al's (2010) chronology of stages for 'cognitive presence' still apply within our 'professional learning community' and 'mathematical reasoning' frameworks, if not always in a strictly linear sequence - but the importance of some resolution in the form of classroom application of participant learning is, we would argue, enhanced in our context. Since it is argued that learning depends directly on cognitive presence, it would seem that more evidence is needed to probe the potential of approaches within SOL to support its development.

\section{Conclusions}

This study applies the Col framework to teacher education, showing that such models of learning adapt to situations more akin to a 'professional learning community' (Hord, 1997). In particular, the lenses of teaching, social, learner, and cognitive presences (Shea and Bidjerano, 2010) have methodological value in highlighting areas of opportunity for developing pedagogical approaches, though possibilities are often particular to an enactment: our presenters and participants both report some challenges, but also some opportunities, within each 'presence' in the SOL mode. 
With social presence, some participants report having the confidence to make contributions in a relatively strange group is a challenge; however, the possibility of remaining anonymous opens up opportunities. For teaching presence, formative assessment and harnessing of peer support are more limited in SOL, but the course can be structured over a sustained time, which has proved problematic for face-toface modes. In terms of learner presence, maintaining concentration in webinars is an issue, but geographical freedom means the course is potentially more widely accessible. Finally, for cognitive presence, physical modelling of classroom pedagogy is limited, but the gap between sessions allows for reflection. In each case, the presenters have been able to develop pedagogical approaches specific to the software which address the concerns at least in part, in ways which participants say they value - and which they claim contribute to the utility and purpose of the course.

Importantly, the study contributes to evidence regarding the pedagogic affordances and limitations of SOL courses for mathematics teacher education. In our context, learning outcomes from the two modes differ in significant ways. There are clear advantages to SOL courses in being able to spread learning episodes over time, and removing barriers such as travel/location. However, the limitations on social interaction in the SOL environment mean that formative assessment of participants' learning requires particular attention. In addition, whilst there is some evidence learning of subject knowledge is comparable to that achieved face-to-face, acquisition of pedagogical content knowledge currently appears, in this enactment, more limited in the SOL environment: it seems much more difficult to develop participants' thinking about mathematics pedagogy successfully when valued underlying principles can only be partially modelled. That might be particularly the case when, as with our participants, teachers are working near the limits of their subject knowledge.

Tool use provides a critical case in this respect: digital tools transfer well to the SOL environment precisely because their use online aligns well with their use in face-to-face sessions, largely preserving the intended modelling of mathematics pedagogy. In contrast, the use of physical tools focused on SPK learning still, for us, requires significant development before effectiveness approaches that achieved face-to-face.

Overall, our evidence suggests difficulties in developing participants' thinking about mathematics pedagogy might be attributable to their more limited cognitive engagement in our own approach to webinar pedagogy - but the possibilities for developing that are constrained, in some instances. Iterative reflec- 
tion on, and analysis of, videos of episodes focusing on mathematics pedagogy have not yet, though, suggested significant further changes that should be adopted.

A clear implication of this study is that SOL approaches to teacher professional development need careful and continued development and evaluation: they do not routinely transfer from face-to-face situations, and indeed in many respects appear to be particular to the outcomes valued and technologies adopted. However, we cite instances of SOL approaches further informing face-to-face pedagogy, and apparently delivering benefits for face-to-face learning. Studies of particular instantiations will therefore remain valuable to our growing understanding of how we can best harness the potential of developing modes of distance learning. Of course, care needs to be taken not to over-interpret findings. Influence on enactment at school classroom level, a key test of effectiveness of the approaches employed, remains to be further investigated, though as indicated, early signs are encouraging.

In summary, then, we have shown that moving teaching online is not necessarily a cheap and convenient option whose impact can be assumed equivalent to that achieved face-to-face, but that an active focus on developing SOL approaches can prove beneficial. We have drawn attention to a theoretical lens that illuminates areas ripe for intervention, though often in ways specific to the technology-related enactment adopted. In our enactment, participants' learning of subject knowledge in a SOL environment appears to be comparable to that achieved face-to-face, but their pedagogical content knowledge acquisition is currently more limited. We have explored the use of tools within learning for teaching Alevel Mathematics, showing that digital tools transfer well to this webinar software, but the use of physical tools still requires significant development. Finally, we have also pointed to ways in which approaches developed to address challenges within a SOL environment can have benefits for a face-to-face course.

\section{Acknowledgement:}

The reported study was funded by the Further Mathematics Support Programme, a DfE initiative. We are also grateful to the participants and colleagues who contributed their reflections, and in particular to Cathy Smith for her contributions to thinking about the nature of effective pedagogy. 


\section{References}

Ainley, J., Pratt, D. and A. Hansen (2006) Connecting engagement and focus in pedagogic task design British Educational Research Journal 32/1, 23-3.

Alexander, M., Lignugaris-Kraft, B. and Forbush, D. (2007) Online mathematics methods course evaluation: Student outcomes, generalization, and pupil performance. Teacher Education and Special Education, 30: 199-216.

Annand, D. (2011). Social Presence within the Community of Inquiry Framework The International Review of Research in Open and Distributed Learning, 12/5, 1-18

Anthony, G. and Walshaw, M. (2009). Characteristics of effective teaching of mathematics: a view from the west Journal of Mathematics Education 2/3, 147-164

Ball, D. L., Thames, M. H., and Phelps, G. (2008). Content knowledge for teaching: what makes it special? Journal of Teacher Education, 59/5, 389-407.

Bates, M., Phalen, L. and C. Moran (2016) Online professional development: a primer Phi Delta Kappan 34, 70-73

Baumert, J., Kunter, M., Blum, W., Brunner, M., Voss, T., Jordan, A., and . . Tsai, Y.-M. (2010). Teachers' mathematical knowledge, cognitive activation in the classroom, and student progress. American Educational Research Journal, 47, 133-180.

Charmaz, K. (2006). Constructing Grounded Theory: A Practical Guide through Qualitative Analysis. Thousand Oaks: Sage Publications.

Comas-Quinn, A. (2011). Learning to teach online or learning to become an online teacher: an exploration of teachers' experiences in a blended learning course. ReCALL, 23/3, 218-232.

De Pomerai, S and Tripconey, S (2011). Live Online Professional Development for Mathematics Teachers. Proceedings of the 10th International Conference on Technology in Mathematics Teaching. http://mccabeme.myweb.port.ac.uk/ictmt10proceedings2.pdf

Garrison, D. R., Anderson, T., and Archer, W. (2010). The first decade of the community of inquiry framework: A retrospective. The Internet and Higher Education, 13(1/2), 5-9

Golding, J. (2017) Mathematics teacher capacity for change Oxford Review of Education 43/4, 502-517.

Hodgen, J. and Wiliam, D. (2006) Mathematics inside the black box: assessment for learning in the mathematics classroom. NFER, London

Hord, S. M. (1997). Professional Learning Communities: Communities of Continuous Inquiry and Improvement. Austin, Texas: Southwest Educational Development Laboratory.

Jones, M., and Ryan, J. (Eds.). (2014). Successful Teacher Education: Partnerships, Reflective Practice and the Place of Technology. Springer.

Joubert, M. and Sutherland, R. (2009) A perspective on the literature: CPD for teachers of mathematics. Sheffield: NCETM

Kissau, S. (2014) Instructional delivery and second language teacher candidate performance: Online vs face-toface. Computer Assisted Language Learning. DOI:10.1080/09588221.2014.881389.

Merriam, S.B. (2001) Andragogy and self-directed learning: Pillars of adult learning theory. New Directions for Adult and Continuing Education 89, 10-18

Mitchell, C. J. 1984. Typicality and the Case Study. In Ethnographic Research: A Guide to General Conduct, edited by R.F. Ellen, 238-241. New York: Academic Press.

Rourke, L., and Kanuka, H. (2009). Learning in communities of inquiry: A review of the literature. Journal of Distance Education, 23/1, 19-48

Shea, P., and Bidjerano, T. (2010). Learning presence: Towards a theory of self-efficacy, self-regulation, and the development of a communities of inquiry in online and blended learning environments. Computers and Education, 55/1, 1721-1731.

Smith, C. and N. Bretscher (2018) Designing teacher education for pre-university mathematics: articulating and operationalising pedagogic messages, this volume

Stevenson, I. (2002) Microworlds and direct manipulation environments: the case of Newtonian mechanics Journal of Educational Computing Research, 27/1, 167-183. 
Jennie Golding is a lecturer in Mathematics Education at University College London Institute of Education. Her background is in the teaching of mathematics from pre-school to university entrance level and in teacher initial and continuing education, but she now works in mathematics education research and research supervision. Her current foci are policy enactment and the development of teacher capacity.

Nicola Bretscher is a lecturer in Mathematics Education at University College London Institute of Education. Her research interests centre around teacher knowledge and technology use in mathematics education. Her teaching involves work on teacher education programmes, and supervising post-graduate and research students. 